\title{
Article \\ PD-L1 Expression Correlated with p53 Expression in Pediatric Glioblastoma Multiforme
}

\author{
Jakub Litak ${ }^{1}\left(\mathbb{D}\right.$, Wiesława Grajkowska ${ }^{2}$, Justyna Szumiło ${ }^{3}$, Paweł Krukow ${ }^{4}\left(\mathbb{D}\right.$, Ryszard Maciejewski ${ }^{5}{ }^{(0}$, \\ Jacek Roliński ${ }^{1, *} *$ and Cezary Grochowski ${ }^{6, *}$
}

1 Department of Immunology, Medical University of Lublin, Chodźki 4a, 20-093 Lublin, Poland; jakub.litak@gmail.com

2 Department of Pathology, The Children's Memorial Health Institute, Aleja Dzieci Polskich 20, 04-730 Warsaw, Poland; W.Grajkowska@ipczd.pl

3 Chair and Department of Clinical Pathomorphology, Medical University of Lublin, 20-093 Lublin, Poland; justynaszumilo@umlub.pl

4 Department of Clinical Neuropsychiatry, Medical University of Lublin, 20-439 Lublin, Poland; pawelkrukow@umlub.pl

5 Department of Anatomy, Medical University of Lublin, 20-400 Lublin, Poland; maciejewski.r@gmail.com

6 Laboratory of Virtual Man, Chair of Anatomy, Medical University of Lublin, 20-093 Lublin, Poland

* Correspondence: jacek.rolinski@gmail.com (J.R.); cezary.grochowski@o2.pl (C.G.)

check for

updates

Citation: Litak, J.; Grajkowska, W.; Szumiło, J.; Krukow, P.; Maciejewski, R.; Roliński, J.; Grochowski, C. PD-L1 Expression Correlated with p53 Expression in Pediatric Glioblastoma Multiforme. Brain Sci. 2021, 11, 262. https://doi.org/10.3390/brainsci1102 0262

Academic Editors: Milica Pešić, Pilar Sánchez Gómez and Lisa Oliver

Received: 17 December 2020

Accepted: 16 February 2021

Published: 19 February 2021

Publisher's Note: MDPI stays neutral with regard to jurisdictional claims in published maps and institutional affiliations.

Copyright: (c) 2021 by the authors. Licensee MDPI, Basel, Switzerland. This article is an open access article distributed under the terms and conditions of the Creative Commons Attribution (CC BY) license (https:// creativecommons.org/licenses/by/ $4.0 /)$.

\begin{abstract}
High-grade gliomas are infrequent in the pediatric population compared to adults, nevertheless, mortality and morbidity caused by malignant gliomas in this group of patients remain significant. PD-L1 and PD-1 Immune checkpoints (IC) molecules maintain immunological balance between activation and suppression. Eighteen patients with a histopathological diagnosis of pediatric glioblastoma multiforme (GBM, WHO IV) were studied. In total, PD-L1 expression was detected in 8 patients (44\%). The molecular aspect of IC and immunotherapy targeted on PD-1/PD-L1 axis in pediatric population may be a promising adjuvant therapy in pediatric glioblastoma multiform treatment, however, this subject requires further investigation.
\end{abstract}

Keywords: pediatric glioblastoma multiforme; PD-L1; GBM

\section{Introduction}

High-grade gliomas are infrequent in the pediatric population compared to adults, nevertheless, mortality and morbidity caused by malignant gliomas in this group of patients remain significant. The incidence of high-grade gliomas is 10\%. Moreover, GBM incidence varies between 3 and $15 \%$ of all primary central nervous system tumors. Despite treatment, long-term outcomes are generally poor. The five year survival time for pediatric patients is ca. 20\% [1]. Glioblastoma Multiforme patients older than 3 years of age are treated with surgery, adjuvant chemo and radiotherapy. In younger patients' radiotherapy should be delayed to avoid significant adverse effects affecting the developing brain tissue. Optimal therapeutic strategy is still uncertain [2]. Current studies point at molecular aspects of the underlying neoplastic processes as the target of modern therapies [3,4].

Immune checkpoints (IC) PD-L1 and PD-1 maintain the immunological balance between activation and suppression. The PD-1/PD-L1 axis controls the processes of negative selection concerning lymphocytes, becoming auto reactive in secondary and primary lymphoid organs. PD-1/PD-L1 knock-out animal models present aggressive autoimmunity. GBM cells self-induce PD-L1 expression by multi receptor activation such as IFNGR, IFNAR, EGFR, TLR. PD-L1 expression in GBM activates subunits of PD-1 on the microglia surface and suppress $\mathrm{T}$ cell response [5].

PD-1/PD-L1 ligation activates the SHP-1/SHP-2 complex and recruits it to interact with ITSM. ITSM is an intercellular tail attached to transmembrane region of PD-1. This 
process promotes ZAP 70, PKC, and CD3 dephosphorylation. In parallel, the Ras -MEKERK and PI3K-Akt pathways are also inactivated. These disturbances globally inhibit the anti-tumor response and thus encourages the invasion of glioblastoma [6]. Overexpressed PD-L1 in GBM cells induces the apoptosis of T cells and activates T-reg cells in close microenvironment, promoting the immune escape of GBM. Relevant research works indicate the GBM expression of PD-L1 as a tumor biomarker [7]. The successful blockage of immune checkpoints in melanoma adult patients has been underlined in several studies. The promising results of IC inhibition bring new insight in oncology of brain tumors [8]. The effectiveness of Pembrolizumab, Duravalumab, Nivolumab, Ipilimumab, and Pidilizumab, members of PD-L1/PD-1 inhibitors, have been thoroughly analyzed in ongoing trials [9-12].

TP53 is the most frequently deregulated gene in carcinogenesis. The modified product of TP53 transcription and translation, the loss of p53 has been implicated in migration, the evasion of apoptosis, proliferation, and invasion of glioblastoma cells. The expression of p53 correlates with unfavorable outcomes, highlighting its crucial role in glioblastoma therapy. Olig2 expression determines oligodendroglial differentiation and plays crucial role as a prognostic factor in glioma classification.

Ki 67 is a nuclear protein associated with cell cycle and proliferation. As a non-histone protein connected with ribosomal RNA and transcription processes, it is a sensitive marker of differentiating cells [13-16].

The presented study evaluates the PD-L1 level in 18 pediatric GBM pediatric patients. To our best knowledge, this is the first study analyzing the expression of PD-L1 in such a number of patients with a homogenous histopathological diagnosis of glioblastoma multiforme (WHO G IV). Moreover, a correlation between PD-1 occurrence with p53, Olig2 and Ki 67 expression is performed in order to find significant molecular interplay in pediatric glioma tissue.

\section{Methods}

\subsection{Subjects}

Eighteen patients with a histopathological diagnosis of pediatric Glioblastoma Multiforme (GBM, WHO IV) were randomly selected for the study from the Children's Memorial Health Institute database in Warsaw, Poland, from 2014 to 2019. Clinical and histopathological data were collected on the basis of medical documentation (Tables 1-4). The histopathological diagnosis of GBM was performed according to the WHO guidelines by a board-certified neuropathologist (W.G.). An age below 18 as well as the diagnosis of GBM were the only inclusion criteria. A board-certified pathologist (J.S.) performed all tumor scoring for PD-L1. This research was approved by the local medical ethics committee of the Medical University of Lublin (KE-0254/330/2019) and was carried out in compliance with national legislation and the Declaration of Helsinki.

Table 1. Selected demographical and clinical data of patients enrolled to the study.

\begin{tabular}{cc}
\hline \multicolumn{2}{c}{ Mean Age 10, 74 Years (min. 4/12; max. 17) } \\
Characteristic & No. (\%) \\
Male & Gander \\
Female & $12(66 \%)$ \\
& $6(33 \%)$ \\
Primary & Primary/Secondary \\
Secondary & $18(100 \%)$ \\
\hline
\end{tabular}


Table 1. Cont.

\begin{tabular}{ccc}
\hline \multicolumn{2}{c}{ Mean Age 10, 74 Years (min. 4/12; max. 17) } \\
Characteristic & No. (\%) \\
Total resection & Surgical Treatment \\
Subtotal & $10(55 \%)$ \\
Biopsy & $5(28 \%)$ \\
Yes & Adjuvant treatment & \\
No & & $17(94 \%)$ \\
& & $1(6 \%)$ \\
\hline
\end{tabular}

Table 2. Summary of patients' characteristics.

\begin{tabular}{cc}
\hline Location & No. (\%) \\
\hline Left temporal lobe & $n=527 \%$ \\
Left frontal lobe & $n=422 \%$ \\
Brainstem & $n=211 \%$ \\
Cerebellum Vermis & $n=211 \%$ \\
Left occipital lobe & $n=15 \%$ \\
Right parietal lobe & $n=15 \%$ \\
Right thalamus & $n=15 \%$ \\
Right frontal lobe & $n=15 \%$ \\
Right temporal lobe & $n=15 \%$ \\
\hline
\end{tabular}

Table 3. Location of Glioblastoma Multiforme (GBM) infiltration among the GBM pediatric cohort $(N=18)$.

\begin{tabular}{|c|c|c|c|c|c|c|}
\hline \multirow{2}{*}{$\frac{\text { Subject No }}{1}$} & \multicolumn{2}{|c|}{ Age (Years) } & \multirow{2}{*}{$\frac{\text { Gender }}{\text { Glioblastoma Multiforme }}$} & \multirow{2}{*}{$\begin{array}{c}\text { Histological Diagnosis } \quad \text { Tumor Location } \\
\text { Left temporal lobe }\end{array}$} & \multirow{2}{*}{$\begin{array}{l}\text { Ki67 (\%) } \\
\text { Negative }\end{array}$} & \multirow{2}{*}{$\begin{array}{c}\text { PD-L1 (\%) } \\
\text { Negative }\end{array}$} \\
\hline & 6 & M & & & & \\
\hline 2 & 11 & M & Glioblastoma Multiforme & Left frontal lobe & Negative & Negative \\
\hline 3 & 9 & $\mathrm{~F}$ & Glioblastoma Multiforme & Left temporal lobe & 28 & Positive (5) \\
\hline 4 & 14 & $\mathrm{~F}$ & Glioblastoma Multiforme & Left occipital lobe & 34 & Negative \\
\hline 5 & 17 & $\mathrm{~F}$ & Glioblastoma Multiforme & Right frontal lobe & 8 & Negative \\
\hline 6 & 5 & $\mathrm{M}$ & Glioblastoma Multiforme & Pons & 26 & Negative \\
\hline 7 & 6 & $\mathrm{M}$ & Glioblastoma Multiforme & Left frontal lobe & 32 & Positive (50) \\
\hline 8 & 14 & M & Glioblastoma Multiforme & Right parietal lobe & 50 & Positive (5) \\
\hline 9 & 8 & M & Glioblastoma Multiforme & Left temporal lobe & Negative & Positive (55) \\
\hline 10 & 9 & M & Glioblastoma Multiforme & Left Frontal lobe & Negative & Negative \\
\hline 11 & 12 & M & Glioblastoma Multiforme & Right thalamus & 55 & Positive (10) \\
\hline 12 & 14 & $\mathrm{~F}$ & Glioblastoma Multiforme & Right temporal lobe & Negative & Negative \\
\hline 13 & 4 & $\mathrm{M}$ & Glioblastoma Multiforme & Left frontal lobe & 8 & Negative \\
\hline 14 & 17 & M & Glioblastoma Multiforme & Cerebellum Vermis & 30 & Negative \\
\hline 15 & 17 & $\mathrm{M}$ & Glioblastoma Multiforme & Left temporal lobe & 35 & Negative \\
\hline 16 & $4 / 12$ & $\mathrm{~F}$ & Glioblastoma Multiforme & Left temporal lobe & 30 & Positive (60) \\
\hline 17 & 14 & $\mathrm{~F}$ & Glioblastoma Multiforme & Pons & 32 & Positive (10) \\
\hline 18 & 16 & M & Glioblastoma Multiforme & Cerebellum Vermis & 30 & Positive (5) \\
\hline
\end{tabular}

Table 4. Percentage distribution of molecules expression among the GBM pediatric cohort $(N=18)$.

\begin{tabular}{cc}
\hline Molecule & Grade/No./(\%) \\
\hline & $0 n=10(55 \%)$ \\
$1 n=5(28 \%)$ \\
$2 n=1(5 \%)$ \\
PD-L1 & $3 n=2(11 \%)$ \\
\hline GFAP & $0 n=4(22 \%)$ \\
& $1 n=14(78 \%)$ \\
\hline \multirow{2}{*}{ Olig 2 } & $0 n=14(78 \%)$ \\
& $1 n=4(22 \%)$ \\
\hline
\end{tabular}


Table 4. Cont.

\begin{tabular}{cc}
\hline Molecule & Grade/No./(\%) \\
\hline \multirow{2}{*}{ Ki 67} & $0 n=5(27 \%)$ \\
& $1 n=2(11 \%)$ \\
$2 n=0(0 \%)$ \\
$3 n=11(61 \%)$ \\
\hline \multirow{2}{*}{ p53 } & $0 n=9(50 \%)$ \\
& $1 n=9(50 \%)$ \\
\hline \multirow{2}{*}{ Synaptophysin } & $0 n=17(94 \%)$ \\
& $1 n=1(5 \%)$ \\
\hline
\end{tabular}

$n$-number of cases, percentage distribution (\%); PD-L1 expression grading 0 none 1 weak $<20 \% 2$ moderate $20-40 \% 3$ high $>40 \%$; GFAP expression grading 0 none 1 present; Olig 2 expression grading 0 none 1 present; Ki 67 expression grading 0 none 1 weak $<10 \% 2$ moderate $10-25 \% 3>25 \%$ high; Synaptophysin expression grading 0 none 1 present; p53 expression grading 0 none 1 present.

\subsection{Tissue Histology and Collection Process}

The tissue was collected during standard tumor resection. The samples were preserved using $4 \%$ phosphate buffered formaldehyde and paraffin-embedded with standard procedures.

H\&E staining was performed on $4 \mu \mathrm{m}$ paraffin sections using standard protocols. Immunohistochemistry was applied using an autostainer (Dako) after heat-induced epitope retrieval in a citrate buffer.

\subsection{Immunohistochemistry}

Formalin-fixed paraffin-embedded tumors of pediatric glioblastoma were cut using a microtome into a $4 \mu \mathrm{m}$ slices, which were placed on a Thermo Scientific ${ }^{\mathrm{TM}}$ SuperFrost Plus Slides for a better tissue adhesion in order to perform immunohistochemistry (IHC). The analysis was performed on a Dako Omnis IHC platform (GI100, Santa Clara, CA, USA). Selected reagents were used in the IHC analysis: PD-L1 IHC 22C3 pharmDx staining set (GE006) including monoclonal PD-L1 antibody 22C3 clone (Dako Omnis, Santa Clara, CA, USA), negative control (Dako Omnis, Santa Clara, CA, USA), high pH detective sys- tem EnVision Flex Mini Kit (Dako Omnis, Santa Clara, CA, USA, GV823), wash buffer (20x) (GC807, Dako Omnis, Santa Clara, CA, USA). In order to remove the paraffin, a low $\mathrm{pH}$ Envision Flex Target Retrieval Solution (Dako Omnis, Santa Clara, CA, USA) was used. Tonsil tissue was used as a positive control and Negative Control Reagent was used for the negative control.

PD-L1 was assessed using PD-L1 IHC 22C3 pharmDx staining protocol and for the negative control PD-L1 IHC 22C3 pharmDx Negative Control Reagent staining protocol.

\subsection{Statistical Analysis}

Quantitative characteristics of the group were presented as means and standard deviations (M, SD) for parametric variables and as percentages and frequencies for nonparametric values.

The planned correlations between biomarkers such as PD-L1, p53, Olig2, Ki 67, due to non-parametric type of variables, were computed with an application of Spearman's $\mathrm{R}$ coefficient. To verify possible differences between subgroups selected on the basis of criteria such as sex (male/female), hemisphere affected by neoplasm (right/left), and supratentorial versus subtentorial location of pathology, the non-parametric Mann-Whitney $\mathrm{U}$ test was used due to the small number of observations in these subgroups and the ordinal level of analyzed variables. For all statistic tests, the threshold of significance was set at $\mathrm{p}$ 0.05, adjusted for Bonferroni correction in case of multiple testing. 


\section{Results}

\subsection{Subsection}

The number of GBM pediatric patients enrolled in the study was 18 . The mean age at final diagnosis day was 10, 74 y.0. ( $\mathrm{SD}=5.05)$, ranged (min. 4 months, max. 17 years). Six female and 12 male patients (33\% vs. 66\%) were included. All the patients had the same diagnosis-Glioblastoma Multiforme (G IV). The study cohort received surgical intervention, and 17 out of 18 individuals underwent adjuvant treatment (Tables 1 and 2).

All the patients had a single lesion. Fourteen lesions were presented in the supratentorial location $(77 \%)$ versus 4 in subtentorial cases $(33 \%)$. The lesion within the left hemisphere was observed in 10 cases (55\%) versus 4 in right (22\%); additionally, 4 patients presented midline infiltration (22\%) (Table 3).

\subsection{PD-L1 Status}

PD-L1 staining was detected mainly in glioblastoma cells and was graded in a 4-stage intensity scale 0 none; 1 weak $<20 \% ; 2$ moderate $20-40 \% ; 3$ high $>40 \%$. In total, PD-L1 expression was detected in 8 patients (44\%): 5 cases with mild expression, 1 case with moderate, and 2 with high levels of expression (Figure 1, Table 3).
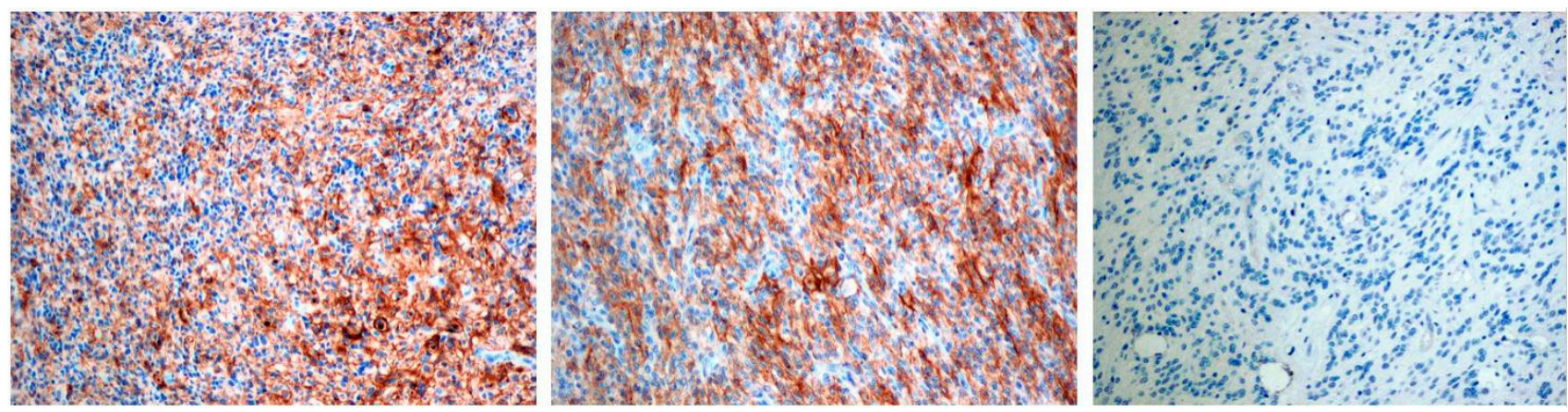

Figure 1. The first two pictures present positive PD-L1 immunostaining in pGBM cells, the last picture presents negative PD-L1 immunostaining. Objective magnification $\times 10$ for each photo.

\subsection{Molecular Status}

All tumor samples were investigated for GFAP, Olig2, Ki 67, p53 and Synaptophysin expression. Scale 0-none 1-present. Ki 67 was evaluated in a 4-grade expression scale 0 -none 1-weak 2-moderate 3-high. GFAP expression was detected in 4 cases (22\%). The occurrence of Olig 2 protein was found in 4 out of 18 cases (22\%). Thirteen patients (72\%) presented Ki 67 expression, 2 patients with weak and 11 with high level of expression. p53 was detected in 9 patients. Only one patient was detected as a case with synaptophysin expression (Table 4).

The hypothesis of PD-L1 correlation with chosen molecular patterns was put forward. Our consideration focused mainly on p53, Olig2, and Ki 67. A positive relationship between PD-L1 and Olig2 R $=0.61, p<0.01$ was found and was determined to be statistically significant. The same results were presented by PD-L1 and p53 correlation $\mathrm{R}=057, p<0.05$. No statistically significant correlation was found between PD-L1 and Ki 67 pair $\mathrm{R}=0.38$ $p>0.05$ (Table 5).

We also investigated the differences concerning biological parameters such as location in two subgroups supratentorial and subtentorial location. The lack of statistically significant differences (all $p>0.05$ ) was found in this analysis. The same results were obtained concerning the comparison (Left/Right) subgroups (all $p>0.05$ ).

Additionally, there were no differences in range of occurrence of biological parameters such as gender and age (all $p>0.05$, Mann-Whitney $\mathrm{U}$ test).

To sum up, our study revealed PD-L1 statistically significant correlations with p53 and Olig2 protein in pediatric population of GBM patients. The lack of a significant relationship 
with Ki67 was confirmed. Biological aspects such as sex, location, and left/right brain hemisphere had no significance.

Table 5. Results of statistical analysis concerning PD-L1 correlations.

$\frac{\text { Statistical Analysis }}{\frac{\mathrm{PD}-\mathrm{L} 1 / \mathrm{p} 53 \mathrm{R}=0.38 p<0.05 * \mathrm{PD}-\mathrm{L} 1 / \mathrm{Olig} 2 \mathrm{R}=0.61 p<0.01 * \mathrm{PD}-\mathrm{L} 1 / \mathrm{Ki} 67 \mathrm{R}=0.36 p>0.05 \text { ** }}{{ }^{*} \text { statistical significance; }{ }^{* *} \text { no statistical significance. }}}$

\section{Discussion}

The presented study revealed that PD-L1 expression is present in pediatric glioblastoma multiforme patients. Different levels of expression oscillated around $45 \%$ in 8 out 18 cases. There are few reports in the literature concerning Pd-L1 expression in children with malignant glioma. A Similar observation was made by Allison et al. [17] This study demonstrated that half of 14 cases cohort diagnosed with LGG presented PD-L1 expression [17]. Majzner et al. [18] identified PD-L1 in 6 out of 20 cases with pediatric high-grade glioma [18]. Interestingly, the intensity of PD-L1 occurrence corresponds with an effective response to ICIs related pathway [19]. A meta-analysis performed by Hao et al. [20] analyzed 9 studies of adult PD-L1 positive glioblastoma patients [20], which suggested the high incidence of PD-L1 to be connected with poor patient survival. No differences were found between PD-L1 and gender as well as age, which was similar to results in this study. This relation was also observed in non-small cell lung cancer (NSCLC) treated with pembrolizumab, where the expression intensity was over $50 \%$ and PD-L1 expression was linked with better treatment response [21]. Another study concerning PD-L1 occurrence in adult glioblastoma patient indicated a higher level of expression at $88 \%$. The analyzed cohort was significantly larger, had contained 117 cases. These findings clearly confirm experimental models based on the hypothesis of PD-1/P PD-L1 axis have a prominent role in forming favorable microenvironment for gliomatous infiltration [22]. Al Harbi et al. [23] presented results of nivolumab, PD-1/PD-L1 axis inhibitor in pediatric glioblastoma patient resulting in a $60 \%$ reduction of GBM infiltration, improvement in clinical status, and continuous 10-month durable response [23]. Moreover, the study performed by Gorsi et al. [24] indicated better results of Nivolumab treatment in patients with a higher rate of PD-L1 comparing to those without expression. Interestingly, the progression free survival (PFS) in PD-L1 positive group versus PD-L1 negative was 13.7 weeks vs. 4.2 weeks ( $p=0.08)$ [24].

The p53 protein, called the "Genome Guardian", functions as a regulator of transcription, promotor of mitotic cycle arrest, integrator of stress signals, and initiator of apoptosis. Additionally, it has protective properties concerning genome integrity. The mutation of TP53 is connected with glioma progression. The p53 protein is associated with more proliferative, less apoptotic, and more invasive phenotype of primary GBM. The deregulation in p53 signaling pathway is one of the most commonly found epigenetic disorders with incidence around $84 \%$ in adult population $[25,26]$. Our study demonstrates $50 \%$ occurrence rate of p53 in IHC analysis, which is similar to the results presented by Suri et al., who demonstrated p53 expression level oscillating ca. $63 \%$ in a group of 30 glioblastoma pediatric cases [27]. The differences between adult and pediatric GBM were explained by Watanabe et al. [28]. Their study indicated lower p53 accumulation in primary GBM affecting commonly pediatric patients compared to secondary being more popular among adults ( $25 \%$ vs. $65 \%$ ) [28]. Pollack et al [29] had similar results concerning p53 expression oscillating ca. $58 \%$ of all pediatric glioblastomas. Moreover, the level of p53 expression was correlated with PFS rate (5 years) in cohort of 74 pediatric patients. Interestingly, the group with p53 low expression had higher PFS at 5 year than group with p53 over-expression $(44 \pm 6 \%$ vs. $17 \pm 6 \%)(p=0.001)$ [29].

Olig2 protein is commonly promoted in adult gliomas controlling oligodendrocytes development and expressed mainly in LGG. Pediatric glioma tumors present different genomic profile. Pediatric glioblastomas have the highest ratio of Olig2 occurrence, which are Ki-67 positive (mean 16.3\%). Otero et al. presented results concerning Olig2 expression 
in 90 patients of different brain tumors. Among them, only 4 were diagnosed with GBM (WHO G IV) characterized with the highest Mean Olig2 score. Our study indicates a $22 \%$ expression of Olig2 in glioblastoma multiforme cohort. In GBM Olig2 seems to be prominent GSC indicator and Olig2 expression was associated with Ki67 occurrence. Moreover, $88 \%$ of Ki 67 positive cells were Olig2 positive in pediatric glioblastoma [30]. This study indicated PD-L1/Olig2 correlation as a statistically significant (PD-L1/Olig2 $\mathrm{R}=0.61 p<0.01$ ) and this relation suggests polymorphous character of GBM tissue, however, it requires further investigation.

Ki 67 levels in glioblastomas are relatively high comparing to other brain cancers. Its expression is active throughout all phases of the cancer cell cycle excluding the resting phase. Several studies have tried to evaluate the level of expression with uncertain outcomes. The study performed by Alkhaibary et al. [31] presented the results excluding a significant correlation of Ki67 expression and overall survival in adult patient [32]. In Sharma et al.'s [31] study, Ki67 expression among GBM pediatric patients was relatively higher compared to those another brain tumor. They also found no significant correlation between K67 rate and outcome [31]. Our results suggest lack of significant correlation between PD-L1 and Ki67 (PD-L1/Ki $67 \mathrm{R}=0.36 p>0.05$ ).

This study investigated significant correlation between PD-L1 and p53 expression in the pediatric GBM population (PD-L1/p53 R $=0.38 p<0.05$ ). These biological molecules have been proven to have unfavorable prognostic value. The synergistic effect of both could strengthen unsuccessful outcome. Cortez et al. [33] propose a novel mechanism of p53 interplay with PD-L1 expression through miRNA-34. This short miRNA molecule promotes the immune evasion of glioblastoma [33]. Some relations concerning PD-L1 and p53 expression were investigated in 976 adult Glioblastoma samples confirming our results. Further investigation on glioblastoma pediatric cohorts is required [34]. Clinical trials concerning IC inhibitors such as antiPD-1/PD-L1 agents bring a new hope for pediatric population suffering from glioblastoma multiforme. Despite uncertain results with pembrolizumab, in heterogeneous groups of patients with gbm, including small cohorts of pediatric patients, further immunological and epigenetic profiling is required to minimize the impact of these efficacy-reducing factors [35,36].

Only the precise molecular screening of treated cohort and meticulous investigation of biological mechanisms can optimize qualification for adequate treatment [37-45].

\section{Conclusions}

The analysis of the pediatric cohort presented in this study brings interesting results. PD- L1 correlation with p53 expression could be an interesting area to look for prognostic properties of both. The molecular aspect of IC and immunotherapy targeted on PD$1 /$ PD-L1 axis in pediatric population may be a promising adjuvant therapy in pediatric glioblastoma multiform treatment, however, this subject requires further investigation in further studies.

Author Contributions: Data curation, J.S., P.K. and C.G.; Formal analysis, J.L., W.G., J.S. and J.R.; Funding acquisition, C.G. Methodology, J.S. and J.R.; Project administration, R.M. and C.G.; Supervision, J.R. and C.G.; Writing—original draft, J.L., W.G. and C.G.; Writing—review \& editing, R.M. and J.R. All authors have read and agreed to the published version of the manuscript.

Funding: This research received no external funding.

Institutional Review Board Statement: This research was approved by the local medical ethics committee of the Medical University of Lublin (KE-0254/330/2019) and was carried out in compliance with national legislation and the Declaration of Helsinki.

Informed Consent Statement: Informed consent was obtained from all subjects involved in the study.

Data Availability Statement: The data presented in this study are available on request from the corresponding author. The data are not publicly available due to lack of institutional online datebase.

Conflicts of Interest: The authors declare no conflict of interest. 


\section{References}

1. Jones, C.; Karajannis, M.A.; Jones, D.T.W.; Kieran, M.W.; Monje, M.; Baker, S.J.; Becher, O.J.; Cho, Y.-J.; Gupta, N.; Hawkins, C.; et al. Pediatric high-grade glioma: Biologically and clinically in need of new thinking. Neuro Oncol. 2016, 19, $153-161$. [CrossRef]

2. Jones, D.T.W.; Kieran, M.W.; Bouffet, E.; Alexandrescu, S.; Bandopadhayay, P.; Bornhorst, M.; Ellison, D.; Fangusaro, J.; Fisher, M.J.; Foreman, N.; et al. Pediatric low- grade gliomas: Next biologically driven steps. Neuro Oncol. 2018, 20, 160-173. [CrossRef] [PubMed]

3. Litak, J.; Grochowski, C.; Litak, J.; Osuchowska, I.; Gosik, K.; Radzikowska, E.; Kamieniak, P.; Rolinski, J. TLR-4 Signaling vs. Immune Checkpoints, miRNAs Molecules, Cancer Stem Cells, and Wingless-Signaling Interplay in Glioblastoma MultiformeFuture Perspectives. Int. J. Mol. Sci. 2020, 21, 3114. [CrossRef]

4. Mazurek, M.; Litak, J.; Kamieniak, P.; Osuchowska, I.; Maciejewski, R.; Roliński, J.; Grajkowska, W.; Grochowski, C. Micro RNA Molecules as Modulators of Treatment Resistance, Immune Checkpoints Controllers and Sensitive Biomarkers in Glioblastoma Multiforme. Int. J. Mol. Sci. 2020, 21, 1507. [CrossRef]

5. Litak, J.; Mazurek, M.; Grochowski, C.; Kamieniak, P.; Roliński, J. PD-L1/PD-1 Axis in Glioblastoma Multiforme. Int. J. Mol. Sci. 2019, 20, 5347. [CrossRef]

6. Dong, Y.; Sun, Q.; Zhang, X. PD-1 and its ligands are important immune checkpoints in cancer. Oncotarget 2017, 8, $2171-2186$. [CrossRef]

7. Nduom, E.K.; Wei, J.; Yaghi, N.K.; Huang, N.; Kong, L.-Y.; Gabrusiewicz, K.; Ling, X.; Zhou, S.; Ivan, C.; Chen, J.Q.; et al. PD-L1 expression and prognostic impact in glioblastoma. Neuro Oncol. 2016, 18, 195-205. [CrossRef]

8. Sanders, S.; Debinski, W. Challenges to Successful Implementation of the Immune Checkpoint Inhibitors for Treatment of Glioblastoma. Int. J. Mol. Sci. 2020, 21, 2759. [CrossRef]

9. Mahoney, K.M.; Freeman, G.J.; McDermott, D.F. The Next Immune-Checkpoint Inhibitors: PD-1/PD-L1 Blockade in Melanoma. Clin. Ther. 2015, 37, 764-782. [CrossRef] [PubMed]

10. Kooshkaki, O.; Derakhshani, A.; Hosseinkhani, N.; Torabi, M.; Safaei, S.; Brunetti, O.; Racanelli, V.; Silvestris, N.; Baradaran, B. Combination of Ipilimumab and Nivolumab in Cancers: From Clinical Practice to Ongoing Clinical Trials. Int. J. Mol. Sci. 2020, 21, 4427. [CrossRef]

11. Huddleston, C.A.; Weinberg, A.D.; Parker, D.C. OX40 (CD134) engagement drives differentiation of CD4p T cells to effector cells. Eur. J. Immunol. 2006, 36, 1093-1103. [CrossRef]

12. Messenheimer, D.J.; Jensen, S.M.; Afentoulis, M.E.; Wegmann, K.W.; Feng, Z.; Friedman, D.J.; Gough, M.J.; Urba, W.J.; Fox, B.A. Timing of PD-1 blockade is critical to effective combination immunotherapy with anti-OX40. Clin. Cancer Res. 2017, 23, 6165-6177. [CrossRef]

13. Ludwig, K.; Kornblum, H.I. Molecular markers in glioma. J. Neurooncol. 2017, 134, 505-512. [CrossRef] [PubMed]

14. Kosty, J.; Lu, F.; Kupp, R.; Mehta, S.; Lu, Q.R. Harnessing OLIG2 function in tumorigenicity and plasticity to target malignant gliomas. Cell Cycle 2017, 16, 1654-1660. [CrossRef]

15. Elmaci, İ.; Altinoz, M.A.; Bolukbasi, F.H.; Yapicier, O.; Sav, A. Paradoxical results obtained with Ki67-labeling and PHH3-mitosis index in glial tumors: A literature analysis. Clin. Neuropathol. 2017, 36, 272-282. [CrossRef]

16. Cahill, D.P.; Sloan, A.E.; Nahed, B.V.; Aldape, K.D.; Louis, D.N.; Ryken, T.C.; Kalkanis, S.N.; Olson, J.J. The role of neuropathology in the management of patients with diffuse low grade glioma: A systematic review and evidence-based clinical practice guideline. J. Neurooncol. 2015, 125, 531-549. [CrossRef]

17. Martin, A.M.; Bell, W.R.; Yuan, M.; Harris, L.; Poore, B.; Arnold, A.; Engle, E.L.; Asnaghi, L.; Lim, M.; Raabe, E.H.; et al. PD-L1 Expres- sion in Pediatric Low-Grade Gliomas Is Independent of BRAF V600E Mutational Status. J. Neuropathol. Exp. Neurol. 2019, 79, 74-85. [CrossRef] [PubMed]

18. Majzner, R.G.; Martinez, D.; Pawel, B.; Santi, M.; Sorensen, P.; Mackall, C.; Maris, J.M. Assessment of PD-L1 expression and tumor associated immune cells in pediatric cancer tissues. J. Clin. Oncol. 2016, 34, 11542. [CrossRef]

19. Ribas, A.; Hu-Lieskovan, S. What does PD-L1 positive or negative mean? J. Exp. Med. 2016, 213, 2835-2840. [CrossRef]

20. Hao, C.; Chen, G.; Zhao, H.; Li, Y.; Chen, J.; Zhang, H.; Li, S.; Zhao, Y.; Chen, F.; Li, W.; et al. PD-L1 Expression in Glioblastoma, the Clinical and Prognostic Significance: A Systematic Literature Review and Meta-Analysis. Front. Oncol. 2020, 10, 1015. [CrossRef]

21. Reck, M.; Rodríguez-Abreu, D.; Robinson, A.G.; Hui, R.; Csőszi, T.; Fülöp, A.; Gottfried, M.; Peled, N.; Tafreshi, A.; Cuffe, S.; et al. Pembrolizumab versus chemotherapy for PD-L1-positive non-small-cell lung cancer. N. Engl. J. Med. 2016, 375, 1823-1833. [CrossRef]

22. Berghoff, A.S.; Kiesel, B.; Widhalm, G.; Rajky, O.; Ricken, G.; Wöhrer, A.; Dieckmann, K.; Filipits, M.; Brandstetter, A.; Weller, M.; et al. Programmed death ligand 1 expression and tumor- infiltrating lymphocytes in glioblastoma. Neuro Oncol. 2015, 17, 1064-1075. [CrossRef]

23. AlHarbi, M.; Ali Mobark, N.; Almubarak, L.; Aljelaify, R.; AlSaeed, M.; Almutairi, A.; Alqubaishi, F.; Hussain, M.E.; Balbaid, A.A.O.; Marie, A.S.; et al. Durable Response to Nivolumab in a Pediatric Patient with Refractory Glioblastoma and Constitutional Biallelic Mismatch Repair Deficiency. Oncologist 2018, 23, 1401-1406. [CrossRef]

24. Gorsi, H.S.; Malicki, D.M.; Barsan, V.; Tumblin, M.; Yeh-Nayre, L.; Milburn, M.; Elster, J.D.; Crawford, J.R. Nivolumab in the Treatment of Recurrent or Refractory Pediatric Brain Tumors: A Single Institutional Experience. J. Pediatr. Hematol. 2019, 41, e235-e241. [CrossRef] 
25. Louis, D.N.; Perry, A.; Reifenberger, G.; Von Deimling, A.; Figarella-Branger, D.; Cavenee, W.K.; Ohgaki, H.; Wiestler, O.D.; Kleihues, P.; Ellison, D.W. The 2016 World Health Organization Classification of Tumors of the Central Nervous System: A summary. Acta Neuropathol. 2016, 131, 803-820. [CrossRef]

26. Zhang, Y.; Dube, C.; Gibert, M., Jr.; Cruickshanks, N.; Wang, B.; Coughlan, M.; Yang, Y.; Setiady, I.; Deveau, C.; Saoud, K.; et al. The p53 Pathway in Glioblastoma. Cancers (Basel) 2018, 10, 297. [CrossRef]

27. Suri, V.; Das, P.; Jain, A.; Sharma, M.C.; Borkar, S.A.; Suri, A.; Gupta, D.; Sarkar, C. Pediatric glioblastomas: A histopathological and molecular genetic study. Neuro Oncol. 2009, 11, 274-280. [CrossRef] [PubMed]

28. Watanabe, K.; Tachibana, O.; Sata, K.; Yonekawa, Y.; Kleihues, P.; Ohgaki, H. Overexpression of the EGF receptor and p53 mutations are mutually exclusive in the evolution of primary and secondary glioblastomas. Brain Pathol. 1996, 6, 217-224. [CrossRef]

29. Pollack, I.F.; Finkelstein, S.D.; Woods, J.; Burnham, J.; Holmes, E.J.; Hamilton, R.L.; Yates, A.J.; Boyett, J.M.; Finlay, J.L.; Sposto, R. Expression of p53 and prognosis in children with malignant gliomas. N. Engl. J. Med. 2002, 346, 420-427. [CrossRef]

30. Otero, J.J.; Rowitch, D.; Vandenberg, S. OLIG2 is differentially expressed in pediatric astrocytic and in ependymal neoplasms. J. Neuro Oncol. 2011, 104, 423-438. [CrossRef]

31. Shoaib, Y.; Sharma, V.; Gupta, L.N.; Dagar, A. P53 and Ki-67 Expression in Primary Pediatric Brain Tumors: Does it Correlate with Presentation, Histological Grade, and Outcome? Asian J. Neurosurg. 2018, 13, 1026-1032. [CrossRef] [PubMed]

32. Alkhaibary, A.; Alassiri, A.H.; AlSufiani, F.; Alharbi, M.A. Ki-67 labeling index in glioblastoma; does it really matter? Hematol. Stem Cell Ther. 2019, 12, 82-88. [CrossRef]

33. Cortez, M.A.; Ivan, C.; Valdecanas, D.; Wang, X.; Peltier, H.J.; Ye, Y.; Araujo, L.; Carbone, D.P.; Shilo, K.; Giri, D.K.; et al. PDL1 Regulation by p53 via miR-34. J. Natl. Cancer Inst. 2016, 108. [CrossRef]

34. Wang, Z.; Zhang, C.; Liu, X.; Wang, Z.; Sun, L.; Li, G.; Liang, J.; Hu, H.; Liu, Y.; Zhang, W.; et al. Molecular and clinical characterization of PD-L1 expression at transcriptional level via 976 sam- ples of brain glioma. OncoImmunology 2016, 5, e1196310. [CrossRef]

35. Blumenthal, D.T.; Yalon, M.; Vainer, G.W.; Lossos, A.; Yust, S.; Tzach, L.; Cagnano, E.; Limon, D.; Bokstein, F. Pembrolizumab: First experience with recurrent primary central nervous system (CNS) tumors. J. Neurooncol. 2016, 129, 453-460. [CrossRef] [PubMed]

36. Lombardi, G.; Barresi, V.; Indraccolo, S.; Simbolo, M.; Fassan, M.; Mandruzzato, S.; Simonelli, M.; Caccese, M.; Pizzi, M.; Fassina, A.; et al. Pembrolizumab Activity in Recurrent High-Grade Gliomas with Partial or Complete Loss of Mismatch Repair Protein Expression: A Monocentric, Observational and Prospective Pilot Study. Cancers (Basel) 2020, 12, 2283. [CrossRef]

37. Cloughesy, T.F.; Mochizuki, A.Y.; Orpilla, J.R.; Hugo, W.; Lee, A.H.; Davidson, T.B.; Wang, A.C.; Ellingson, B.M.; Rytlewski, J.A.; Sanders, C.M.; et al. Neoadjuvant anti-PD-1 immunotherapy promotes a survival benefit with intratumoral and systemic immune responses in recurrent glioblas- toma. Nat. Med. 2019, 25, 477-486. [CrossRef]

38. Schalper, K.A.; Rodriguez-Ruiz, M.E.; Diez-Valle, R.; López-Janeiro, A.; Porciuncula, A.; Idoate, M.A.; Inogés, S.; De Andrea, C.; De Cerio, A.L.-D.; Tejada, S.; et al. Neoadjuvant nivolumab modifies the tumor immune microenvironment in resec- table glioblastoma. Nat. Med. 2019, 25, 470-476. [CrossRef]

39. Jan, C.I.; Tsai, W.C.; Harn, H.J.; Shyu, W.C.; Liu, M.C.; Lu, H.M.; Chiu, S.C.; Cho, D.Y. Predictors of Response to Autologous Dendritic Cell Therapy in Glioblastoma Multiforme. Front. Immunol. 2018, 9. [CrossRef]

40. Lynes, J.; Jackson, S.; Sanchez, V.; Dominah, G.; Wang, X.; Kuek, A.; Hayes, C.P.; Benzo, S.; Scott, G.C.; Chittiboina, P.; et al. Cytokine Microdialysis for Real-Time Immune Monitoring in Glioblastoma Patients Undergoing Checkpoint Blockade. Neurosurgery 2019, 84, 945-953. [CrossRef]

41. Wang, Q.T.; Nie, Y.; Sun, S.N.; Lin, T.; Han, R.J.; Jiang, J.; Li, Z.; Li, J.Q.; Xiao, Y.P.; Fan, Y.Y.; et al. Tumor-associated antigen-based personalized dendritic cell vaccine in solid tumor patients. Cancer Immunol. Immunother. 2020, 69, 1375-1387. [CrossRef] [PubMed]

42. Curry, W.T., Jr.; Gorrepati, R.; Piesche, M.; Sasada, T.; Agarwalla, P.; Jones, P.S.; Gerstner, E.R.; Golby, A.J.; Batchelor, T.T.; Wen, P.Y.; et al. Vaccination with Irradiated Autologous Tumor Cells Mixed with Irradiated GM-K562 Cells Stimulates Antitumor Immunity and T Lymphocyte Activation in Patients with Recurrent Malignant Glioma. Clin. Cancer Res. 2016, 22, 2885-2896. [CrossRef]

43. Caccese, M.; Indraccolo, S.; Zagonel, V.; Lombardi, G. PD-1/PD-L1 immune-checkpoint inhibitors in glioblastoma: A concise review. Crit. Rev. Oncol. Hematol. 2019, 135, 128-134. [CrossRef]

44. Park, J.; Kim, C.G.; Shim, J.-K.; Kim, J.H.; Lee, H.; Lee, J.E.; Kim, M.H.; Haam, K.; Jung, I.; Park, S.-H.; et al. Effect of combined anti-PD-1 and temozolomide therapy in glioblastoma. OncoImmunology 2019, 8, e1525243. [CrossRef] [PubMed]

45. Mazurek, M.; Grochowski, C.; Litak, J.; Osuchowska, I.; Maciejewski, R.; Kamieniak, P. Recent Trends of microRNA Significance in Pediatric Population Glioblastoma and Current Knowledge of Micro RNA Function in Glioblastoma Multiforme. Int. J. Mol. Sci. 2020, 21, 3046. [CrossRef] 